\title{
Investigando o Comportamento na Web de um Grupo de Bacharelandos da Área de Tecnologia da Informação
}

\author{
Davi J. Vittorazzi ${ }^{1}$, Nelcileno V. S. Araújo², Patricia C. de Souza ${ }^{2}$ \\ ${ }^{1}$ Faculdade de Comunicação e Artes - Universidade Federal de Mato Grosso (UFMT)- \\ Cuiabá, MT - Brasil \\ ${ }^{2}$ Laboratório de Ambientes Virtuais Interativos (LAVI) - Instituto de Computação - \\ Universidade Federal de Mato Grosso (UFMT) - Cuiabá, MT - Brasil \\ davivittorazzi@gmail.com, nelcileno@ic.ufmt.br, patricia@ic.ufmt.br
}

Abstract. With the increase in the number of digital crimes in Brazil in recent years, it is essential to change the attitude of the user. From this, we investigated the behavior of a group of graduating students in the area of information technology, in relation to digital security and privacy. The obtained data refute the statement that formal knowledge in information technology helps in safe behavior on the Internet, since most students behaved in an insecure manner. The article points out that a more direct communication to students through extension actions and complementary activities in order to facilitate the understanding of this topic.

Resumo. Com o aumento nos últimos anos da quantidade de crimes digitais no Brasil torna-se essencial a mudança de postura por parte do usuário. A partir disso, investigou-se neste trabalho o comportamento de um grupo de bacharelandos na área de tecnologia da informação, com relação a segurança e privacidade digital. Os dados apresentados refutam a afirmação que o conhecimento formal em tecnologia da informação auxilia no comportamento seguro na Internet, uma vez que a maioria dos pesquisados comportava-se de maneira insegura. $O$ trabalho acena que uma comunicação mais direta aos alunos por meio de ações extensionistas e atividades complementares nos cursos podem ajudar na sensibilização sobre o tema.

\section{Contextualização}

A importância de entender e conscientizar usuários frente aos riscos no meio digital pode ser abordado por diversos aspectos, mas fundamentalmente devido ao número de crimes em ambientes virtuais crescente no mundo todo. No Brasil, segundo o relatório do laboratório especializado em segurança cibernético da Startup PSafe, houve um crescimento de 95,9\% de ataques cibernéticos só no primeiro semestre de 2018, o equivalente a 120,7 milhões de ataques.

Por meio do projeto de extensão "Internet Segura: sensibilizando e conscientizando a sociedade sobre os riscos na $\mathrm{Web}^{1}{ }^{1}$, vigente no ano de 2019 , e do projeto de pesquisa "Investigação de Novos Paradigmas que Favoreçam o Entendimento e Decisões Assertivas acerca dos Riscos de Privacidade e Segurança Digital", de vigência 2018-2020, da Universidade Federal de Mato Grosso, realizou-se uma pesquisa por meio de questionário

\footnotetext{
${ }^{1}$ https://www.facebook.com/lavisecandpriv/
} 
visando compreender o comportamento dos estudantes do Instituto de Computação quanto à segurança e a privacidade de seus dados no meio digital.

Dessa forma, partimos da hipótese de que os estudantes das áreas da Tecnologia da Informação deveriam ter uma preocupação expressiva quanto ao comportamento na internet, principalmente relacionado a segurança e privacidade. Por outro lado, também apropriamos da possibilidade do comportamento com riscos a própria segurança, tendo em vista o Paradoxo da Privacidade (KOKOLAKIS, 2017) e até mesmo por conta da falta de disciplinas nos currículos acadêmicos que tratam o tema com profundidade e demais meios de conscientização na sociedade sobre os perigos no meio digital e de como manter um comportamento seguro. Entendemos como comportamento seguro diversas medidas que o usuário executa na interação com a tecnologia visando proteger seus dados, como por exemplo, a estratégia utilizada na criação e atualização de senhas.

\section{Trabalhos Relacionados}

Em meio aos trabalhos científicos que dialogam com a temática de segurança no ambiente virtual está o artigo de Marciano e Lima-Marques (2006). Este trabalho envolve a área específica da segurança da informação, que por sua vez propõe a realização de integração de disciplinas das ciências sociais para a elaboração de corpus bem fundamentado para aplicação e acompanhamento de políticas de segurança estruturadas, abrangendo o equilíbrio humano e técnico da segurança da informação, assim também a segurança dos usuários em qualquer ambiente, inclusive virtuais. Segundo os autores, o motivo para analisar a segurança da informação organizacional com viés nas ciências sociais se dá pela informação ser gerada, armazenada, tratada e transmitida com a finalidade da comunicação, sendo esta uma experiência por um processo grupal, nunca isolada.

O trabalho de Raitzl; Aguiar e Godarth (2017) apresenta ainda mais semelhanças com o trabalho desenvolvido, pois os autores fizeram uma pesquisa quantitativa para identificar as variáveis que influenciam no processo de decisão de compra no comércio eletrônico, aplicando um questionário estruturado junto a uma amostra de 78 alunos da pós-graduação da Universidade Estadual do Oeste do Paraná - Campus de Francisco Beltrão.

A pesquisa teve como principal objetivo identificar os hábitos da amostra de consumidores durante a realização de compras online. Assim, observou-se a construção de dimensões benéficas, de barreiras e a dimensão de riscos durante o processo de compra. Esta última foi apontada na pesquisa como uma preocupação de $54 \%$ dos entrevistados. Dessa forma, percebe-se mais uma evidência a preocupação dos usuários quanto à segurança no meio digital.

Por sua vez, a pesquisa feita pela empresa MasterCard (2013), identificou cinco tipos de personas com comportamentos diferentes relacionado a utilização de seus dados na internet e ao consumo online. O estudo destacou que $64 \%$ dos usuários têm noção que seus dados estão sendo utilizados pelas empresas, relevou ainda que a idade não é um fator relevante sobre o comportamento dos usuários. Apontou que $60 \%$ dos consumidores sabem mudar as configurações de privacidade nos navegadores de internet.

\section{Metodologia}

A pesquisa realizada teve como propósito investigar o comportamento de usuários no meio digital. A amostra foi constituída por acadêmicos de graduação de diferentes períodos 
do Instituto de Computação da Universidade Federal de Mato Grosso (UFMT), os quais estavam matriculados em cursos de bacharelado em Ciência da Computação e Sistema de Informação. Além disso, os discentes que responderam à pesquisa estavam matriculados especificamente em uma das três disciplinas: Criptografia e Segurança de Dados, Fundamentos da Computação ou Estágio Supervisionado.

Responderam à pesquisa 67 estudantes, dos cursos de Ciência da Computação e Sistema de Informação. A pesquisa foi aplicada pelo formulário do Google Forms e disponibilizado via Ambiente Virtual de Aprendizagem (AVA), sistema próprio da UFMT no período de 26/07/2019 a 07/08/2019.

Em relação às perguntas disponíveis no formulário, no primeiro bloco buscou-se caracterizar o perfil dos usuários, no segundo foi relacionado aos cuidados que os usuários têm no meio digital, especialmente em dispositivos móveis, e por fim as questões que envolviam o conhecimento dos alunos sobre a legislação brasileira de segurança de dados, como o Marco Civil da Internet (BRASIL, 2014) e a Lei Geral de Proteção de Dados (BRASIL, 2018; BRASIL, 2019).

Após a obtenção das respostas, foi aplicada a Escala de Likert que permite escalonar as respostas em cinco tipos diferentes de concordância para uma questão. A escolha desta escala com opções de 5 itens atesta-se pela facilidade e a rapidez para os entrevistados responderem as perguntas, como apontado por Dalmoro e Mendes Vieira (2013). Em pesquisa sobre a disposição e mensuração de dados por meio da Escala de Likert, os autores verificaram que cinco opções, em comparação com perguntas de três e sete, apresentam-se mais eficiente. Portanto, estipulou-se pesos (P) para cada uma das opções de respostas (R), de 1 a 5. Assim, a opção mais negativa - descrita como "nunca" - representava o peso 1, de modo crescente até que a alternativa mais positiva - descrita como "quase sempre" - que indicada pelo peso 5. A partir disso, multiplicamos o número de respostas de cada alternativa pelo peso. Dessa forma, obtivemos um valor ( $\mathrm{R}$ x $\mathrm{P}$ ) o qual somamos obtendo um total do valor dos pesos e outro das respostas. Tiramos a média entre os valores totais e obtemos um índice que representa a alternativa que representa o comportamento na determinada questão. Assim, tabulamos os dados em gráficos, apontamos para um índice médio que indica uma resposta predominante para cada pergunta feita.

Inicialmente, levantou-se a hipótese para o resultado da pesquisa de que as respostas indicassem que o comportamento dos estudantes fosse propenso a uma atuação de risco na internet. Assim também para o baixo conhecimento relacionado às legislações de segurança de dados no Brasil. Portanto, mesmo que estes estivessem no ambiente de estudos de Tecnologia da Informação, os entrevistados possivelmente seriam leigos sobre os assuntos investigados.

\section{Avaliação do comportamento dos discentes das disciplinas de Estágio Supervisionado, Fundamentos de Computação e Criptografia e Segurança de Dados na internet}

Entre os entrevistados, $62,7 \%$ têm idade entre 18 e 23 anos, o segundo valor mais alto é dos que tem entre 24 e 29 anos, representam $28,4 \%$. O sexo predominante na pesquisa é o masculino, representando $83,6 \%$, enquanto o feminino representa $16,4 \%$. Os estudantes estão matriculados 52,5\% no curso bacharel em Ciência da Computação e 48,5\% bacharel em Sistema da Informação. Quanto ao ingresso dos estudantes na Universidade, os que 
ingressaram no semestre 2019/1 - período da realização da pesquisa -, a maioria, representa $38,2 \%$. Outros ingressos mais expressivos são de 27,9\% em 2017/1; e 16,2\% antes de 2015/1, estes últimos estariam próximos de concluir a graduação.

A Tabela 1 apresenta a primeira questão do formulário relacionado ao comportamento sobre a frequência de alteração de senhas.

Tabela 1 - Frequência de alteração de senhas

\begin{tabular}{|c|c|c|c|}
\hline \multicolumn{4}{|c|}{ Com que frequência você troca sua(s) senha(s) em aplicativos e redes sociais? } \\
\hline Alternativa & Resposta & Peso & $\mathrm{R} \times \mathrm{P}$ \\
\hline Quase Sempre & 1 & 5 & 5 \\
\hline Frequentemente & 2 & 4 & 8 \\
\hline Algumas vezes & 22 & 3 & 66 \\
\hline Raramente & 36 & 2 & 72 \\
\hline Nunca & 6 & 1 & 6 \\
\hline Total & 67 & - & 157 \\
\hline Média & \multicolumn{3}{|c}{$\mathbf{2 , 3 4}$} \\
\hline
\end{tabular}

A partir da análise percebemos que os discentes estão mais próximos em trocar suas senhas raramente ou às vezes. A checagem da veracidade de informações noticiosas antes de compartilhá-las, indica que, frequentemente ou quase sempre há a verificação das mensagens. Quanto à leitura dos termos de uso ao instalar aplicativos nunca ou raramente os usuários leem os termos de uso. Os estudantes que fecham conexão ao sair de um aplicativo ou conta no computador representam que algumas vezes ou frequentemente. Os usuários que enviam informações sensíveis (senhas de bancos, dados pessoais) por meio de aplicativos de mensagens instantâneas apresentou-se que raramente ou algumas vezes o fazem. $O$ índice mediu que raramente ou algumas vezes, os estudantes acessam sites por meio de links anexos em e-mails ou mensagens instantâneas.

Quanto ao nível de confiança na segurança e privacidade ao realizar movimentação financeira na internet pelos entrevistados, o questionário apontou que algumas vezes ou frequentemente, conforme apresentado na Tabela 2. De modo semelhante, a confiança em sistemas operacionais móveis (iOS e Android). Em relação ao conhecimento dos usuários sobre as configurações do sistema móvel, com o exemplo de desativar o assistente de voz, os usuários já ouviram falar algumas vezes ou conhece superficialmente. Assim como mostrou que os entrevistados sabem desativar o histórico de localização superficialmente ou já ouviram falar a respeito. Tal conhecimento superficial ou que já se ouviram falar a respeito, também se aplicou sobre capacidade dos entrevistados em configurar a privacidade e segurança em aplicativos.

Tabela 2 - Nível de confiança da segurança dos dados em transações financeiras

Qual o seu nível de confiança, na segurança e privacidade dos seus dados, ao realizar uma compra/pagamento de serviços (água, luz, internet, telefone) pela Internet?

\begin{tabular}{|c|c|c|c|}
\hline Alternativa & F & Peso & F x P \\
\hline Quase Sempre & 15 & 5 & 75 \\
\hline Frequentemente & 30 & 4 & 120 \\
\hline
\end{tabular}




\begin{tabular}{|c|c|c|c|}
\hline As Vezes & 14 & 3 & 42 \\
\hline Raramente & 3 & 2 & 6 \\
\hline Nunca & 3 & 1 & 3 \\
\hline Total & 65 & & 246 \\
\hline Média & \multicolumn{3}{|c|}{$\mathbf{3 , 7 8}$} \\
\hline
\end{tabular}

Perguntas sobre o conhecimento dos entrevistados em relação a legislação brasileira houve alteração na ordem das respostas. Neste caso, as respostas mais negativas representavam o valor mais próximo a 5, enquanto o valor mais próximo a 1 , representa 0 maior conhecimento. Assim, os estudantes apresentaram-se com conhecimento superficial ou que já ouviram dizer a respeito do Marco Civil da Internet, conforme indicado na Tabela 3. Os entrevistados disseram que já ouviram falar, mas conhecem pouco sobre o que se trata a Lei Geral de Proteção de Dados (LGPD).

\begin{tabular}{|c|c|c|c|}
\hline \multicolumn{4}{|c|}{$\begin{array}{c}\text { Você sabe o que é o Marco Civil da } \\
\text { Internet? }\end{array}$} \\
\hline Alternativa & $\mathbf{F}$ & Peso & $F \times P$ \\
\hline NCNSA & 9 & 1 & 9 \\
\hline OFNSA & 15 & 2 & 30 \\
\hline CS & 15 & 3 & 45 \\
\hline JLOR & 19 & 4 & 76 \\
\hline $\mathrm{JE}$ & 9 & 5 & 45 \\
\hline Total & 67 & & 205 \\
\hline Média & \multicolumn{3}{|c|}{3,05} \\
\hline
\end{tabular}

Apesar do Marco Civil da Internet (BRASIL, 2014) ter sido sancionada pela Presidente da República há cinco anos, os estudantes ainda têm pouco conhecimento sobre uma lei muito importante na área de Tecnologia da Informação.

\section{Considerações Finais}

Apesar da hipótese inicial do trabalho partir do pressuposto de que alunos de cursos da área de tecnologia da informação teriam um comportamento mais cuidadoso no acesso à Internet devido terem mais acesso a informações sobre os riscos de segurança e privacidade na Web, mas o que se observou foi um contraponto. Cerca de $62 \%$ dos discentes responderam que nunca ou raramente trocam a senha de aplicativos e redes sociais que utilizam, demonstrando dessa forma um comportamento bem displicente com relação a segurança pois uma senha quase nunca alterada possui grande probabilidade de ser alvo de um ataque cibernético. A mesma contradição ocorre também quanto à privacidade, quando $95 \%$ dos entrevistados afirmaram que raramente ou nunca leem os termos de uso antes de instalar um aplicativo. Este tipo de comportamento do usuário pode deixá-lo vulnerável quanto a privacidade pois algumas cláusulas do termo de uso podem possibilitar o acesso e a venda de informações sensíveis do usuário. Outro número que refuta nossa hipótese, quando apenas 
$12 \%$ dos pesquisados afirmam saber configurar os parâmetros de segurança e privacidade em aplicativos.

Sendo assim, percebe-se preliminarmente na amostra pesquisada que pessoas com conhecimento formal de computação não estão livres de terem comportamento de risco na Web e poucas delas sabem contramedidas para se proteger de possíveis ataques por meio de aplicativos. Apesar desse cenário, vale salientar que a maioria dos pesquisados responderam não compartilhar notícias sem verificar a veracidade e não enviam informações sensíveis por meio de mensageiros instantâneos. Dessa forma percebe-se que algum caminho foi realizado por parte dos alunos com relação a sensibilização e conscientização sobre segurança e privacidade digital.

Uma maneira de melhorar esses números é investir numa comunicação mais direta aos alunos. Isso pode ser realizado por meio de palestras executadas nas atividades complementares dos cursos, bem como no uso da extensão para trabalhar essa sensibilização e conscientização sobre os riscos na Web.

Em trabalhos futuros pretende-se aplicar uma análise estatística mais aprofundada para verificar a correlação entre as perguntas e como isso pode influenciar em medidas para incentivar o comportamento seguro na Internet.

\section{Referências}

BRASIL. (2014) "Lei $\mathrm{n}^{\mathrm{o}}$ 12965, de 23 de abril de 2014", http://www.planalto.gov.br/ccivil_03/_ato2011-2014/2014/lei/112965.htm

BRASIL (2018) "Lei $\mathrm{n}^{\mathrm{o}}$ 13709, de 14 de agosto de 2018", http://www.planalto.gov.br/ccivil_03/_Ato2015-2018/2018/Lei/L13709.htm.

BRASIL (2019) "Lei $\mathrm{n}^{\mathrm{o}}$ 13853, de 08 de julho de 2019", http://www.planalto.gov.br/ccivil_03/_Ato2019-2022/2019/Lei/L13853.htm.

Dalmoro M. e Mendes Vieira, K. (2013) "Dilemas Na Construção De Escalas Tipo Likert: o número de itens e a disposição influenciam nos resultados?", In: Revista Gestão Organizacional, Vol. 6.

Marciano, J. L. e Lima-marques M. (2006) "O enfoque social da segurança da informação", http://www.scielo.br/scielo.php?script=sci_arttext\&pid=S0100-

$19652006000300009 \& \operatorname{lng}=$ en\&nrm=iso\&tlng=pt.

MASTERCARD (2013) "Around the World in 5 Personas: how global consumers think about their data online!", White paper, https://newsroom.mastercard.com/documents/around-the-world-in-5-personas-howglobal-consumers-think-about-their-data-online/.

Kokolakis, S. (2017) "Privacy Attitudes and Privacy Behaviour: a review of current research of the privacy paradox phenomenon", In: Computers and Security, v. 64, 2017, p. $122-$ 134.

Raitzl, D; Aguiar, J. e Godarth, K. (2017) "Comércio Eletrônico: variáveis condicionantes no processo de decisão de compra online”. In: Revista Brasileira de Sistemas de Informação, Rio de Janeiro, vol. 10, n. 2, pp. 153-170. 